\title{
Reseña
}

\section{Curso masivo online: síntomas sociales en las series de TV del siglo XXI}

\author{
María Victoria Tomasetti* \\ Centro de Día 4, Córdoba, Argentina
}

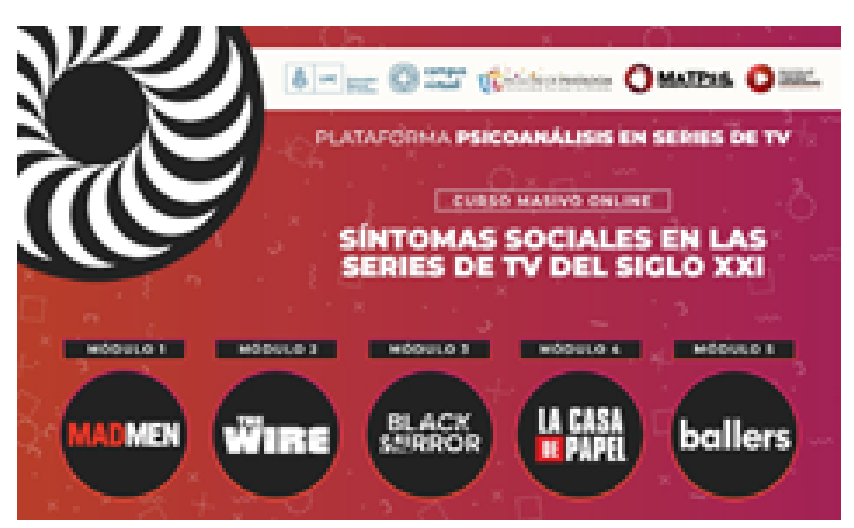

\section{Curso Masivo Online}

Síntomas Sociales en las Series de Televisión del Siglo XXI

MÓDULO 1: "La era de la imagen en Mad Men"

MÓDULO 2: "El inconsciente y la ciudad en la serie The Wire"

MÓDULO 3: "Las grietas de la ciudad en Black Mirror" MODULO 4: "La mujer y los feminismos en La casa de papel"

MÓDULO 5: "Ballers: capitalismo, cuerpos y deporte de alto rendimiento"

\section{"Que renuncie quien no pueda unir a su horizonte la subjetividad de su época” (Lacan, 1953, p. 309).}

Nueva era, otros tiempos, nuevos goces, otros modos, nuevos síntomas. ¿Otra época?

Ensayar un esbozo de respuesta, implica tener en cuenta que la época en la que se enmarcaron los desarrollos de Lacan, dista del tiempo en el que nos encontramos hoy.

Apunto: ¿cuál es nuestra época?

Quienes estamos convocados por el discurso del psicoanálisis, atestiguamos desde hace tiempo, una notable disminución en los efectos del remedio freudiano. $\mathrm{Al}$ interrogante sobre nuestra época, puede decirse que asistimos a la época del Otro que no existe, época de los desengaños, de la errancia tal como lo nombra Miller (2005).

El Nombre del Padre ya no funciona, ya no viene al lugar de solución para dar respuesta ante la angustia. Entonces, ¿con qué nos encontramos hoy?
Como lo propone Miller (2005), hoy nos encontramos con sujetos desengañados, ya no se engañan con el Nombre del Padre ni con la existencia del Otro. Asistimos a una época donde implícita o explícitamente, estamos anoticiados de que el Otro es sólo un semblante. En palabras de Lacan (1976): “podemos prescindir del Nombre del Padre con la condición de servirnos de él” (p. 133), a lo que Miller (2005) agrega: "podemos prescindir del Nombre del Padre en tanto real, a condición de servirnos de él como semblante" (p. 12).

¿Alguna oferta para hacer ante el desengaño? ¿En qué creen los sujetos hoy?

Orientada por un detalle que, sostengo hace signo en la sociedad actual, ¿es posible pensar al fenómeno de las series como un síntoma?

¿Qué le enseñan las series de televisión al psicoanálisis acerca de los síntomas sociales que se presentan en la actualidad? 
Se constata que en los últimos años, el mercado de las series televisivas incorpora a sus tramas, fenómenos y problemáticas de la realidad social contemporánea. Sea por lo que constituyen, como por los fenómenos que dejan entrever, desde la teoría psicoanalítica lacaniana esto puede analizarse como manifestaciones del síntoma social y serán abordados como tales.

Pensar a las series como un síntoma, posibilita capturar a partir del uso ficcional de determinadas tramas y personajes, algo de ese real imposible de nombrar para cada uno de los sujetos que, expectantes, esperan semana tras semana el lanzamiento del próximo episodio. Los de hoy, sujetos descreídos, protagonistas de vidas anónimas y normalizadas donde la ficción les abre paso a la utopía de creer, que al menos por un instante, pueden hallarse soluciones para hacer con eso que no anda.

Así, a partir de este interrogante presento aquí la $I^{\circ}$ Edición de "Síntomas Sociales en las Series de TV del Siglo XXI". Se trata de un Curso Masivo Online (MOOC) perteneciente al Programa de Extensión "Psicoanálisis y Discurso Contemporáneo" llevado adelante por la Maestría en Teoría Psicoanalítica Lacaniana de la Universidad Nacional de Córdoba.

Dirigida a todas aquellas personas familiarizadas con las series que estén interesadas en ampliar su lectura acerca de este producto de la cultura de masas, el MOOC se enmarca en una actividad libre y gratuita a la que puede accederse desde una plataforma virtual.

Así, el mundo reducido a una imagen. La ciudad como ese espacio que llenan quienes la habitan. La segregación siendo efecto de estrategias de dominación. Cuerpos diseñados que circulan como objetos de consumo. Mujeres, en todas sus versiones, encarnando todo aquello que queda por fuera de la norma, siendo la voz de eso que no anda.

Con esto, cinco módulos, cinco tramas. En cada uno, dos participantes, dos miradas. El psicoanálisis no está solo, dialoga con otras voces para abordar algo de lo que atraviesa la pantalla para hacerse escuchar.

Hacia el final, retomo las palabras de Lacan: "Que renuncie quien no puede unir a su horizonte la subjetividad de su época" (Lacan, 1953, p. 309).

De allí, esta nueva propuesta que viene entre los modos de la época. Porque se apuesta a no retroceder, porque hay una causa que antecede. Porque el psicoanálisis tiene para decir y se ofrece a la escucha allí donde, capturados por grandes pantallas y teclados táctiles, la palabra cae, se degrada, se banaliza y hiere. Porque ahí, ante la emergencia de eso que socialmente falla, algo hace síntoma a través del uso indiscriminado de las redes sociales, del cuerpo, de la publicidad, y todo aquello que esté al alcance del consumo a uno y otro lado de la cámara de televisión, a uno y otro lado de la pantalla.

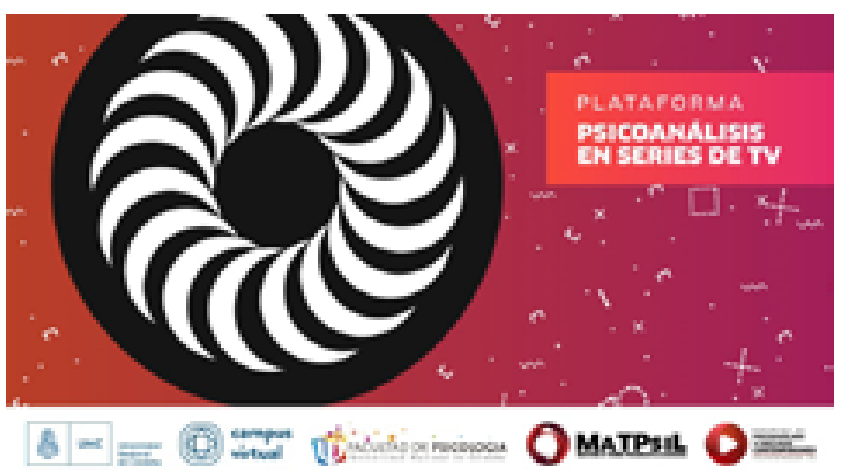

\section{Referencias}

Brodsky, G. (29 y 30 de octubre de 2016). Elogio de la virtualidad. [Blog \#8]. Recuperado de http://www.eol-laplata.org/blog/index. php/elogio-de-la-virtualidad/\#more-3074.

Brodsky, G. (3 de diciembre 2016). Ponencia. En C. Ríos (Presidencia), Elpoder de los objetos. El régimen de la pulsión en la sociedad virtual. Jornadas llevadas a cabo en las III Jornadas EOL Sección La Plata. Buenos Aires, Argentina.

Lacan, J. (1988). Función y campo de la palabra y el lenguaje en psicoanálisis. Escritos 1. Argentina: Siglo XXI.

Lacan, J. (1975-76). El Sinthome. El seminario de Jacques Lacan. Libro 23. Argentina: Paidós.

Miller, J-A (2005). El Otro que no existe y sus comités de ética. Argentina: Paidós. 